\title{
Actuando desde la distancia: GeoVisor una app de lugares seguros y no solamente una app contra la COVID-19
}

\author{
Acting from a distance: GeoVisor an app for safe places and not just an \\ app against COVID-19
}

\section{Atuando à distância: GeoVisor um aplicativo para lugares seguros e não apenas um aplicativo contra COVID-19}

\author{
Juan Manuel Delgado Estrada ${ }^{1,2, a}$, Carlos Bryan Becerra Blaz ${ }^{1, b}$, Mario Rafael Olivas \\ Villanera $^{1, c}$ y Víctor Alexis Bartolomé Liendo Huasco ${ }^{1, d}$ \\ ${ }^{1}$ Universidad Nacional Mayor de San Marcos \\ ${ }^{2}$ Universidad de Barcelona, CLACSO y Unión Geográfica Internacional \\ ajuan.delgado10@unmsm.edu.pe

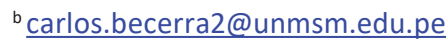 \\ ‘mario.olivas@unmsm.edu.pe \\ dalexis262016@hotmail.com
}

\begin{abstract}
RESUMEN
Este trabajo pretende dar a conocer la propuesta del Aplicativo GeoVisor, situándonos en el contexto de pandemia y las Neogeo - grafías del común practicadas por la población de Jequetepeque. GeoVisor tiene como propósito ser una app contra la COVID - 19 y para la geolocalización de lugares seguros, pero actuando desde la distancia y tomando en cuenta el carácter etnográfico de la población. Un proyecto colaborativo de profesionales en la geotecnologias frente al escenario mundial de la COVID 19 y dentro del contexto peruano, teniendo como área de estudio el Distrito de Jequetepeque en el departamento de la Libertad.
\end{abstract}

\begin{abstract}
This work aims to publicize the GeoVisor Application proposal, placing us in the context of a pandemic and the common Neogeographies practiced by the Jequetepeque population. GeoVisor is intended to be an app against the COVID - 19 and for the geolocation of safe places, but acting from a distance and taking into account the ethnographic nature of the population. A collaborative project of professionals in geotechnologies facing the world scenario of the COVID-19 and within the Peruvian context, having as a study area the District of Jequetepeque in the department of La Libertad.
\end{abstract}

\section{RESUMO}

Este trabalho tem como objetivo apresentar a proposta do Aplicativo Geovisor, colocando-nos no contexto de uma pandemia e da Neogeo - grafia do comum praticada pela população de Jequetepeque.O Geovisor pretende ser um aplicativo contra COVID - 19 e para geolocalização de lugares seguro, mas atuando à distância e tendo em conta a natureza etnográfica da população. Um projeto colaborativo de profissionais de geotecnologia frente ao cenário mundial da COVID - 19 e no contexto peruano, tendo como área de estudo o Distrito de Jequetepeque no departamento de La Libertad. 
PALABRAS CLAVES: GeoVisor; Jequetepeque; Pandemia; Neogeo - grafias.

KEYWORDS: GeoVisor; Jequetepeque; Pandemic; Neogeo - graphies.

PALAVRAS-CHAVE: GeoVisor; Jequetepeque;Pandemia; Neogeo - grafias.

\section{Introducción}

Hoy en día nos encontramos en un contexto de pandemia a causa de la COVID-19, donde la globalización ha tenido mucha influencia. Por este proceso hemos llegado al punto en que la distancia ya no es una barrera geográfica que limita el intercambio comercial y la interconectividad. La rápida propagación del virus ha tomado como aliado a la globalización ya que las sociedades han sido medios de transporte para su rápida distribución, en otras palabras, el aumento de movilidad de las personas han sido el mejor aliado de la COVID-19 tanto para su propagación como distribución. Las escalas de contagio abarcan desde las grandes ciudades hasta las escalas locales en todo el mundo donde el hombre ha llegado a modificar la naturaleza.

En el Perú esta enfermedad se ha expandido de manera rápida sumado a que las medidas no se han ejecutado adecuadamente, esto mismo ha generado que la propagación actualmente se encuentra en aumento. Ciertamente la pandemia ha repercutido en nosotros como una manera de ver nuestras falencias y recayendo con mayor fuerza en el tema de la salud.

El distrito de Jequetepeque tiene como capital al centro poblado que lleva el mismo nombre. Este se encuentra situado en la parte central occidental de la Provincia de Pacasmayo y margen izquierdo del río Jequetepeque. Dentro de un fértil valle del mismo nombre, limita con los distritos de Guadalupe, San José y el distrito de Pacasmayo. Todos estos pertenecen al Departamento de La Libertad. Por último, tiene una población de 4136 habitantes según el censo del 2017 del INEI (Ver Figura 1).

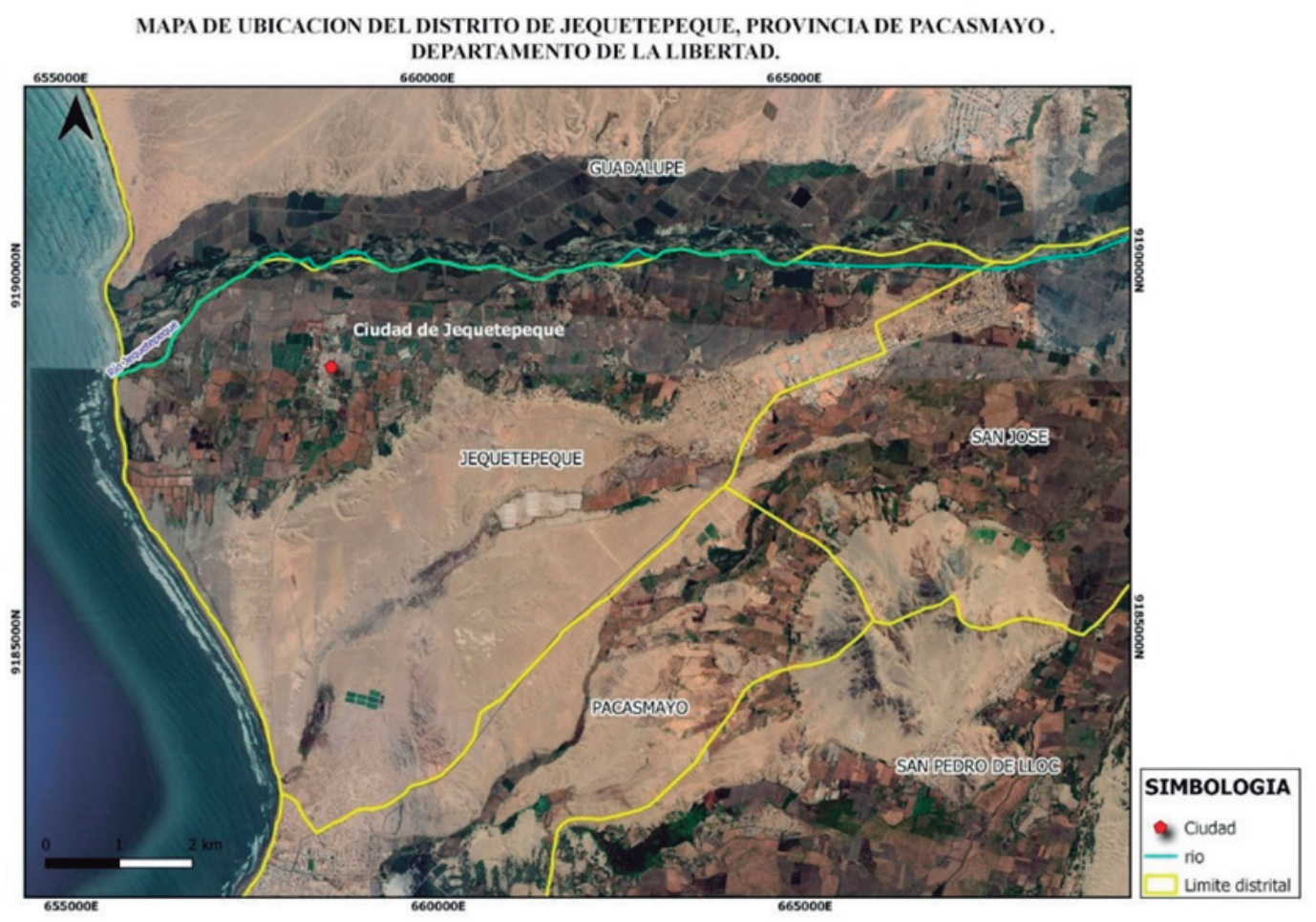

Figura 1. Mapa de ubicación del Distrito de Jequetepeque

Fuente: Elaboración propia por parte de Carlos Bryan Becerra Blaz 
La inmigración china de los coolies posiblemente haya influido en que el valle de Jequetepeque se haya convertido en un gran productor de arroz. Estos comenzaron como una fuerza de trabajo y poco a poco fueron volviéndose propietarios pequeños y medianos que para el año 1950 se convirtieron en haciendas típicas costeñas, pero aun así se necesitaba una obra de mano constante para los cultivos y el yanaconaje fue una manera, basada en la recompensa por las tierras trabajadas del hacendado del valle.

La reforma agraria de 1969 incubó movimientos sociales tantos de base, como asociaciones, colectivos, organizaciones sociales de vecinos, campesinos e indígenas. Estos dos últimos fueron fortalecidos por la reforma agraria de los años 70, desde partidos viejos de izquierda hasta movimientos afectados por el conflicto de uso de la tierra. La gran reforma de la tierra fue dejada a un lado y se empezó a concentrar las tierras para el uso de la agro exportación.

Con la llegada del Gobierno de Fujimori los sindicatos, organización gremiales y sectoriales del campo fueron debilitadas por el régimen, hubo una precarización e informalidad del trabajo, que en Jequetepeque no fue una ajena, más bien en el distrito la actividad agrícola se diversifico y hasta ahora es la fuente principal de empleo. El individualismo es el brazo armado del neoliberalismo, nos decía Milton Santos (2004), en donde nos llama a producir una globalización alternativa al poder hegemónico y del dinero. Esto se acentuó con la llegada del Gobierno Post Fujimori. Entonces, así como existe la triada territorio/territorialidad/territorialización en la escala de Jequetepeque existe hacienda/campesino/comunidad, las cuales se dan por circunstancias particulares, actores en juego de poderes y producción social.

\section{El contexto de la crisis de la Pandemia COVID - 19 en Jequetepeque}

Frente al contexto mundial que se está viviendo con la pandemia del covid-19 el estado peruano decidió tomar diversas medidas para poder reducir el impacto y así evitar situaciones similares de diversos países del mundo donde el virus ha ocasionado grandes pérdidas tanto humanas y económicas.

diversos mecanismos de contingencia fueron aplicados tanto en la parte social para prevenir más contagios, proporcionandoversos bonos a los sectores más bajos del país y en la parte económica para afrontar esta etapa donde la economía se paralizó y decayó en estos últimos meses.

Ya transcurrido 6 meses aproximadamente desde que inició la cuarentena, el sistema de salud viene siendo sobrepasado, en el tema de servicios básicos, fuerzas policiales y militares también siendo contagiados y entre otros. La situación actual del Perú ha visibilizado el trabajo informal y la precariedad del sistema laboral, como consecuencia que este sector tenga que elegir entre seguir trabajando para poder seguir costeando la alimentación de su vivienda o guardar la cuarentena.

Jequetepeque, no cuenta los servicios médicos,personal capacitado einfraestructura requerida para afrontar este virus que viene propagándoserápidamente.. En los distritos rurales, como en el caso de Jequetepeque se caraterizan por una agricultura de escala media y monocultivos, trabajo algo precario, que se podria decir, avalada por el estado con el régimen laboral especial de la agro exportación que nos dejó el presidente Fujimori y el ministro que estaba a cargo de la agricultura José Chlimper en esa época.

Para añadir , al inicio de la pandemia uno de nuestros investigadores tuvo contacto con una persona allegada a uno de los investigadores (Mariana Ponce), la cual lo invitó a conformar un grupo en Facebook que se llamaba "Jequetepeque Unidos", este grupo lo integraban personas que vivían en este distrito y se organizaron para poder afrontar esta amenaza de la COVID - 19 a eso que Rogério Haesbert nos dice 
que quien domina el poder en el territorio es quien ejerce miedo, y en este momento hay una disputa por quién produce más miedo, en nuestro caso de estudio sería Jequetepeque.

\section{La etnografía a la distancia en medio de la pandemia}

La mayoría de nosotros residimos en la ciudad debido a la pandemia actual. El trabajo de campo presencial se encuentra limitada debido a que si se va al lugar de trabajo se estaría llevando el virus hacia los territorios más alejados debido a todo esto se decidió realizar el trabajo de campo a distancia mediante la metodología de la etnografía que trata de aprender los fenómenos sociales en un determinado contexto. Esto implica una profunda descripción de lo que se viene estudiando y también se trata de construir alguna relación o vínculo con las personas oriundas del lugar. Se contactó con un ciudadano de Jequetepeque para que pueda ir a campo ya que él conoce mejor la zona y además las personas sientan un poco más de confianza en el momento de hacer las respectivas preguntas y se pueda recopilar la información requerida y analizarla de manera digital.

Cuando uno piensa inicialmente un trabajo o proyecto con cierta población, lo piensa a partir de experiencias primarias, aun así sea solo un acercamiento. Por eso para nosotros es ideal hacer vínculos desde la distancia con los actores de campo, no solo de contención por este contexto sino también que ellos sean actores claves para que nosotros podamos entender el sentido que la comunidad de Jequetepeque le está dando a estas experiencias vividas. Así podremos entenderlos como se vinculan, sus escenarios, circunscribir sus características individuales y marcar diferencias según los actores sociales del distrito. En otras palabras, son distintos actores sociales y cada uno tiene una manera de pensar. Eso se verá reflejado en la data que recolectemos desde la distancia Además forma parte de la técnica que estamos realizando para vincularnos con la población y comunicarnos. (Vivimos la experiencia sin desplazarnos, pero con cautela ya que no es lo mismo estar presentes en el lugar como no estarlo).

La tecnología que tenemos a disposición nos ha dado la oportunidad de traducir la información que tenemos de manera virtual y así llegar de algún modo a la población del distrito. Es como una forma estratégicamente orientada y parcial de etnografía. Asimismo, nosotros somos intermediarios en el cual nos vinculamos de manera externa e interna y de manera simultánea, pero a su vez buscamos ganar experiencias nuevas en el tiempo, las cuales son importantes para mejorar o reajustar el análisis del contexto. Finalmente se tiene que aprovechar la interacción que se puede tener ya que la información hecha virtualidad se puede transmitir de una persona a otra de manera rápida.

Asimismo, para añadir y debido a la coyuntura actual el método más apropiado que se escogió para realizar el estudio fue el método cualitativo etnográfico observador. participante de forma virtual, realizando mapas de stakeholders, identificando a los que ejercen mayor y menor liderazgo, recolectando información y monitoreando de manera digital las actividades establecidas en la cartografía social, que es algo complicado debido a que no estamos presentes en la misma área de estudio. Se realizaron algunas entrevistas con el método dialéctico para poder elaborar las bases de este informe de investigación. Como dice Carlos Walter Porto-Gonçalves (2015) la geografía debe de dejar de ser sustantivo y ser verbo, porque se confunde lo que se desea como un objeto de estudio, hay que graficar el territorio/ territorialidad/territorialización (Rogério Haesbaert, 2013). En resumen, nosotros podemos vincularnos con la población a la distancia con la tecnología. 


\section{Las Neogeo - grafías del común en la actualidad de Jequetepeque}

En Jequetepeque las autoridades locales como los líderes comunitarios empiezan a participar en conjunto para poder realizar una campaña contra la COVID - 19, todo esto origina una iniciativa por parte de los ciudadanos del distrito. Se empezó a conformar cuadrillas de desinfección con los mismos vecinos que laboran en el campo agrícola con el fin de poder ir a espacios públicos y lugares donde hay una mayor concentración y tránsito de personas como en los alrededores y los frontis de las casas. Un equipo de vecinos conformó un conjunto de garitas como medida de control por parte de la misma población para poder fiscalizar que solo se realicen actividades esenciales como los comercios, entes públicos, la fuerza policial y regular el flujo tanto de ingreso como salida a Jequetepeque. Se mantiene el control de trabajadores provenientes de otros distritos que llegan a Jequetepeque y no cuentan con ningún tipo de protección. En conjunto con las empresas se ejerce un cierto control al ingresar siguiendo los protocolos respectivos,para que los camiones pasen por un arco de desinfección.

Los sectores empresariales desde hace varios años han tenido la hegemonía para poder activar la economía y en esta pandemia al encontrarse varios meses inactivos, sus negocios dejaron de funcionar trayéndoles grandes pérdidas económicas. Debido a esto, las grandes empresas ejercieron una presión al estado peruano para que se reactiven las diversas actividades económicas y que sus negocios ya no se vean más perjudicados en su producción; sin embargo, no tomaron en cuenta a los trabajadores informales e independientes que también se han visto afectados y de alguna manera se encuentran con sus oficios de subsistencia para poder adquirir productos alimentarios y poder pagar sus rentas de alquiler. Ya en la ciudad principal como Lima se activaron algunas actividades, pero con ciertos protocolos para evitar la propagación de la COVID-19.

En el distrito de Jequetepeque actualmente está sucediendo un hecho, en el cual la población está trabajando en conjunto contra la COVID -19 y de esta manera están dejando de lado algunas diferencias en un plano inferior. Este punto de unión para enfrentar a la COVID 19 está llegando a los ojos de las autoridades locales y representantes del estado en el distrito.

Teniendo en cuenta esta condición favorable como es el trabajo en común de la población también hay que añadirle la cantidad mínima de contagiados en el distrito. Ambas condiciones nos van a permitir poder aplicar medidas más adecuadas a la situación, con resultados más eficientes, y de la mano de herramientas de información potentes para la ciudadania; ese es el caso de las herramientas Geotecnologías. Por eso se hace hincapié a que la población pueda contar con este tipo de herramientas para seguir haciéndole frente al vector de contagio, pero de manera más efectiva.

\section{Las Neogeo - tecnologías al servicio del Común}

Viviendo esta experiencia entre todos nosotros, nos ponemos a reflexionar y analizar la oportunidad que tenemos. Luego de observar documentación sobre Apps que utilizan Sistemas de Información Geográfica para enfrentar la COVID 19 y reconocer una realidad favorable que sucede en el distrito, nos convencimos al igual que nuestro investigador principal (Juan Manuel Delgado) que es posible diseñar una App de esas características para el distrito de Jequetepeque.

En primera instancia la idea fue proponer mapas ciudadanos ingestados de geodatos para reconocer síntomas (teletriaje) a fin de tener una métrica geolocalizado de contagios, sus síntomas, manejar los fake news y tratar de entender al vector de contagio. El otro mapa temático dinámico a realizar sería el de las personas que salieron positivo y realizarles un seguimiento de su geolocalización en términos de 
AmigoCloud ${ }^{1}$ se le conoce como "Contact Traicing" que desarrollaron esta propuesta de solución. Uno de manera voluntaria va compartiendo donde estuvo en las últimas 72 horas, inclusive los últimos 15 días previos para poder localizar a los posibles contagiados con el fin de que las personas que puedan visualizar esta información privada estén precavidas, haga memoria, vea sí estuvo en esos puntos de contagio ( supermercados, bancos,etc) y tomen conciencia acatando la cuarentena o si no que las diferentes brigadas de seguimiento de cuarentenas que se conformaron los obligue a cumplirlo, si es posible tenemos que adelantarnos al vector para poder prevenirlo $\mathrm{y}$ controlarlo de una manera adecuada.

Entonces, haciendo un paréntesis de lo redactado hasta ahora llegamos al punto en que buscamos y necesitamos propuestas confiables que tengan una buena base para poder enfrentar el problema de la COVID - 19 en el distrito, pero sobre todo que sean para el común, que se formen vínculos por medio de tecnologías a la distancia o mejor dicho Neo geo- Tecnologías que es lo que somos y que la población sepa aprovecharlas de manera eficaz. Nosotros aparecemos como un proyecto neogeo tecnológico contra la COVID - 19 y nos presentamos como GeoVisor, una propuesta que está conformada por profesionales de diferentes ramas con relación a las neo geotecnologías. Nuestro proyecto tiene experiencia de competencia como proyecto en donde se llegó a postular a un concurso. En este concurso de nombre "TransferenciAP Reto COVID - 19" y organizado por la universidad ESAN junto con el BID (Banco Interamericano de Desarrollo); postularon un promedio de 120 proyectos a nivel de Latinoamérica, la temática principal fue generar algún tipo de tecnología para frenar las diversas consecuencias que el COVID - 19 originó. GeoVisor llegó a la última etapa donde quedamos entre los 10 primeros. Esta experiencia nos sumó ideas y la posibilidad de asesoramiento para poder desarrollar de manera óptima el proyecto.

El objetivo principal de nosotros como proyecto GeoVisor es enfrentar al vector de contagio la COVID - 19 desde la distancia y utilizando la geotecnologia moderna mediante una base de datos abierta con información de posibles focos de contagio, en el cual se podrá realizar un seguimiento de contactos (Contact Tracing), contar con data especifica referido a la situación socioeconómica, geolocalizar puntos de contagio y espacios seguros, intercambiar información entre los usuarios de manera veraz y visualizar estos datos en un aplicativo pero a su vez generando un vínculo de comunicación con la población. Consideramos que somos una opción innovadora y eficaz para responder a la problemática de la COVID - 19 y en el cual la población de Jequetepeque pueda tener una seguridad con la propuesta de Neogeo Tecnología que presentamos.

Por medio de la plataforma AmigoCloud elaboramos 3 formularios base que tiene como finalidad conocer la situación socioeconómica, la salud de la población y la geolocalización de establecimientos seguros frente al COVID - 19. Generamos nuestra propia base de datos con un propósito en común y para la población. De esta manera intentamos graficar un poco más el contexto de GeoVisor en medio de esta Pandemia, como se está trabajando y como aprovechamos tecnologías como Cloud. En general como neogeo - tecnología que somos presentamos una propuesta sólida, aplicada para el Distrito de Jequetepeque y dentro de las posibilidades y oportunidades que nos está brindando este espacio para generar un cambio; viendo provechoso la distancia y no un obstáculo.

\section{Problemáticas y Recomendaciones}

Si bien la problemática general gira en torno a la falta de capacidad del Estado y gobiernos locales en la aplicación de medidas adecuadas contra la COVID - 19.A esto le añadimos el desconocimiento de qué lugares son más seguros para la población.

1 AmigoCloud es una geotecnologia geoespacial simple, pero para la resolución de problemas reales, desde la recolección y visualización de datos, siguiendo con la realización de mapas, analizando el espacio para la toma de decisiones. 
Todos sabemos que se permitió la movilidad de las actividades económicas luego de que la economía entrara en una recesión, trayendo grandes consecuencias sociales y políticas. Es por eso que se está retornando a la normalidad pero en el caso de los trabajadores informales no se le puede hacer un valor de juicio debido a que algunos no estuvieron laborando y de alguna manera necesitan subsistir ya que tampoco fueron acreedores de algunos de los bonos que el estado otorgó.

En Jequetepeque la situación no es ajena a los demás; como la mayoría de lugares el distrito cuenta por un lado con deficiencias de infraestructura de salud y servicios para hacer frente a la COVID - 19 y por el otro, la precariedad del empleo donde la población generalmente se dedica a la agricultura de escala media y monocultivos.

Por otro lado, nosotros como proyecto hemos experimentado problemas y dificultades, los cuales pasan más por un tema de contrastación de recopilación de data de campo para el monitoreo, la presencia de voluntarios o personal con ganas de colaboración, equipos móviles adecuados para el monitoreo y sobre todo más apoyo de las entidades locales del Estado, cabe la redundancia.

Los problemas y dificultades mencionados anteriormente nos ocasionaron un contratiempo ya que teníamos previsto un tiempo determinado para el desarrollo del proyecto.Esto no implica que no haya una evolución en el trabajo elaborado. Todo lo contrario, tenemos una data ordenada, la cual está siendo reajustada y actualizada constantemente para una mayor eficacia, haciendo especial mención a las encuestas de teletriaje (salud y seguimiento de contactos) y socioeconómica.

Con la reactivación económica, el estado estableció protocolos de bioseguridad, los cuales están regulados por el MINSA y monitoreado por los Gobiernos locales. En el caso de que la persona se encuentre sana o asintomático con la COVID -19 se le monitorea con el aplicativo para ver que no hayan estado en lugares que son puntos de contagio.

Asimismo, con el aplicativo se puede observar el historial de sus familiares en su domicilio que hayan sido infectadas por el virus. Con esto se busca identificar a las personas que son casos activos y la información recopilada se cruza con la data del MINSA. Esto se comprueba con la geolocalización del celular e IP de la conexión de su internet o Contact Traicing.

La importancia general de nosotros como proyecto GeoVisor es generar una capacidad de respuesta y solución desde las Neogeo - tecnologías, sumándole las experiencias obtenidas y el trabajo en conjunto. Lo que se busca con la población de Jequetepeque es que ellos puedan tener a la mano herramientas de información y apoyo contra la COVID - 19.

Tener una detección temprana de los casos COVID - 19, así como su respectivo seguimiento va permitirnos dar soluciones ideales frente a este vector de contagio, las cuales se presentan favorables gracias al trabajo en conjunto de la población y la cantidad de mínima de contagios.

Por otro lado, si bien la experiencia se da a la distancia también establecemos vínculos con los distintos actores y tenemos un acercamiento. La idea es fortalecer esos vínculos no solo como una manera de contención frente al contexto de Pandemia sino también que ellos sean actores claves para nosotros y así poder entender el sentido que la comunidad le está dando a estas experiencias vividas.

El trabajo multidisciplinarios en conjunto con el Estado, poblaciones y tecnologías útiles da mejores resultados, pero debido a que el estado no incentiva la inversión en geotecnologías para aplicarlo a una gran escala, solo se está realizando el monitoreo en Jequetepeque con el apoyo de la comunidad de este distrito por ahora. 
Entre toda esta narrativa de hechos, GeoVisor se hace presente como parte de la solución ya que una app móvil y web que permite conocer los niveles de seguridad de los diferentes locales comerciales y públicos de la ciudad. Esta será una herramienta muy útil y práctica para decidir cómo moverse en la ciudad y correr menos riesgos en el escenario mundial de la COVID - 19.

La distancia para nosotros no es obstáculo para brindar soluciones y actuar para la toma de decisiones correctas, las cuales deberían ser un punto de observación para el Estado, de que, si se puede actuar a la distancia, marcar diferencias y generar un ecosistema digital entre la interacción de las empresas, el estado y la población.

Si bien el distrito cuenta con condiciones favorables anteriormente mencionadas como es el trabajo en común que la población de Jequetepeque práctica y la cantidad mínima de contagiados, El monitoreo y seguimiento de contactos (Contact Traicing) es nuestra base, pero además forma parte de un paquete completo. Tenemos una base de datos útil y confiable la cual utilizaremos tanto para el seguimiento de contactos (Contact Traicing), muy importante para evaluar el tema de la salud, para la geolocalización de puntos de contagio y espacios seguros y para el aspecto socioeconómico el cual absorbe las problemáticas que están relacionadas a este.

Todo este proceso de trabajo en equipo nos sitúa como una app no solamente contra la COVID - 19 sino también una app de lugares seguros frente al vector de contagio, estableciendo vínculos claves con los actores y actuando desde la distancia pero sobre todo demostrando que esta no es barrera para brindar soluciones y tomar decisiones de manera adecuada frente al vector de Contagio de la COVID - 19 (Ver Figuras 2-9).

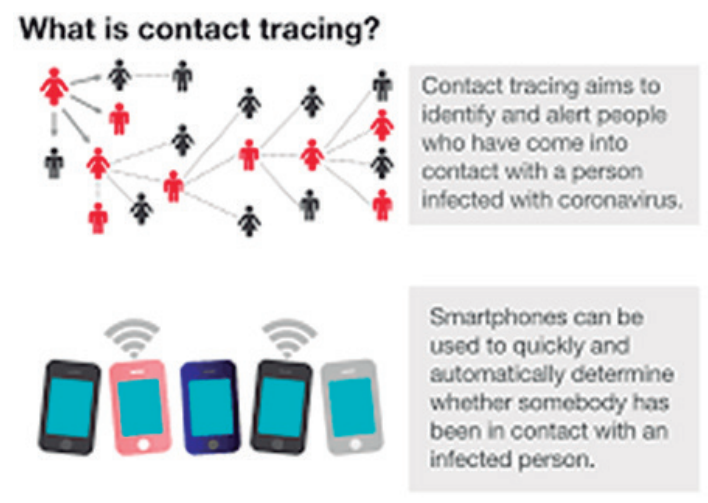

Bas

Figura 2. ¿Qué es el seguimiento de contactos? Fuente: Geovisor

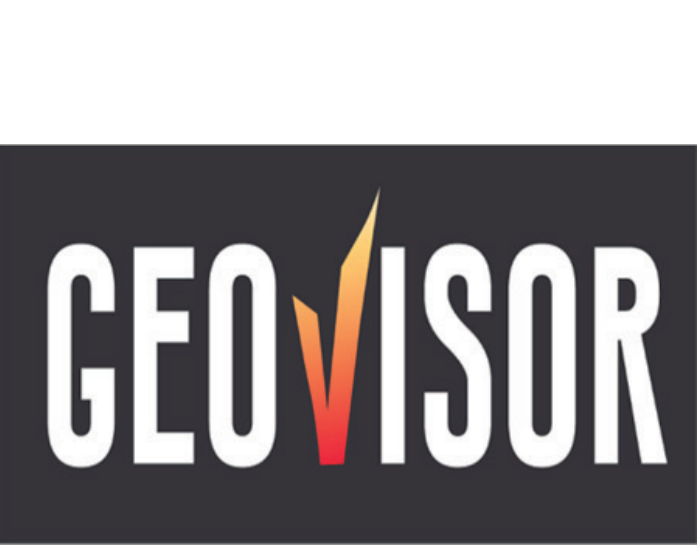

Figura 4. Logo oficial del aplicativo Web Geovisor Fuente: Geovisor

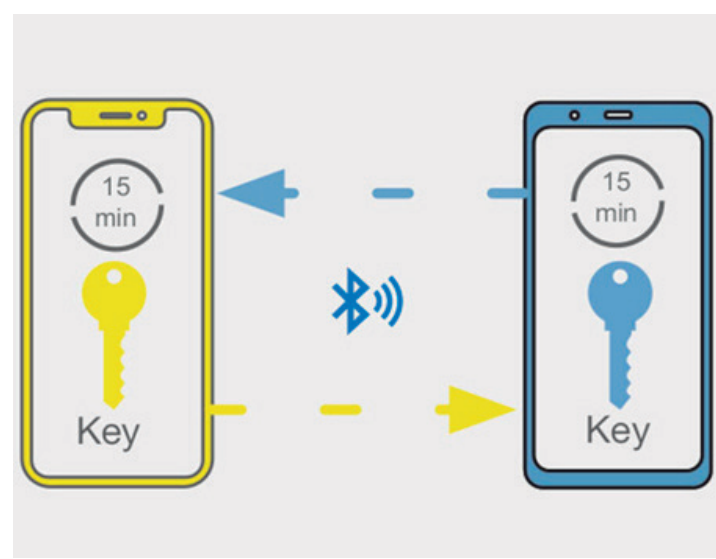

Figura 3. La aplicación Geovisor nos mantiene al tanto mediante el servicio Bluetooh de la cercanía en distancia y tiempo con respecto a otros usuarios.

Fuente: Geovisor

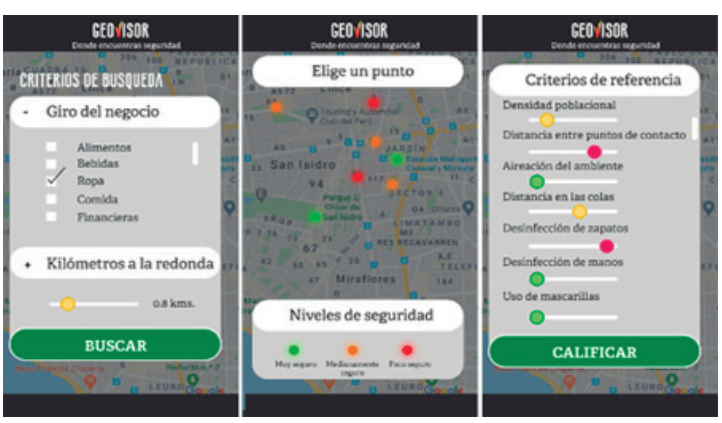

Figura 5. Modelo de Interfaz gráfica del aplicativo Web Geovisor

Fuente: Geovisor 


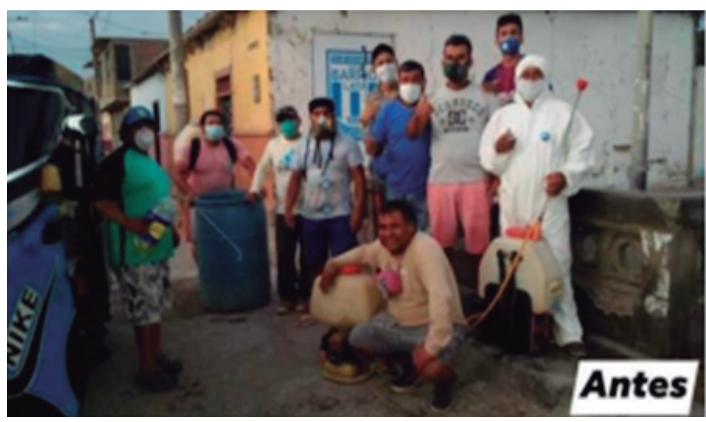

Figura 6. Equipo de preparación antes de la llegad de la COVID -19

Fuente: Municipalidad de Jequetepeque

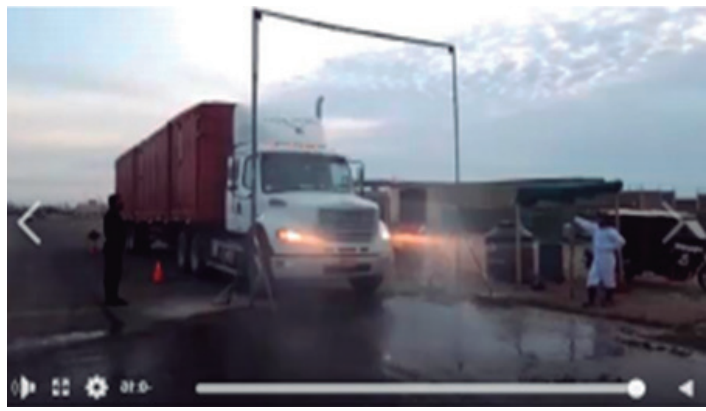

Figura 8. Desinfección medios de transporte Fuente: Municipalidad de Jequetepeque

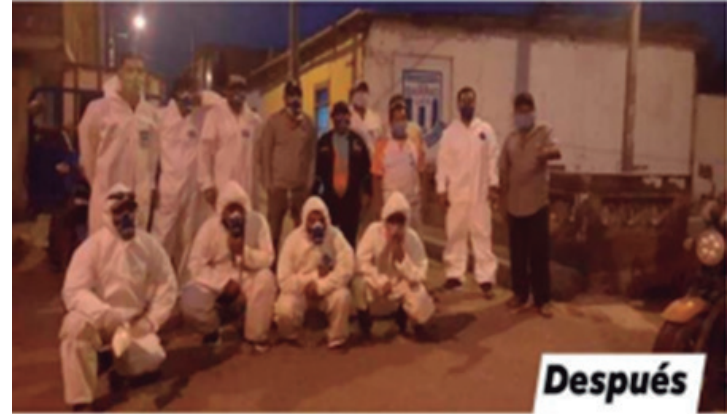

Figura 7. Equipo de preparación después la llegada de la COVID -19

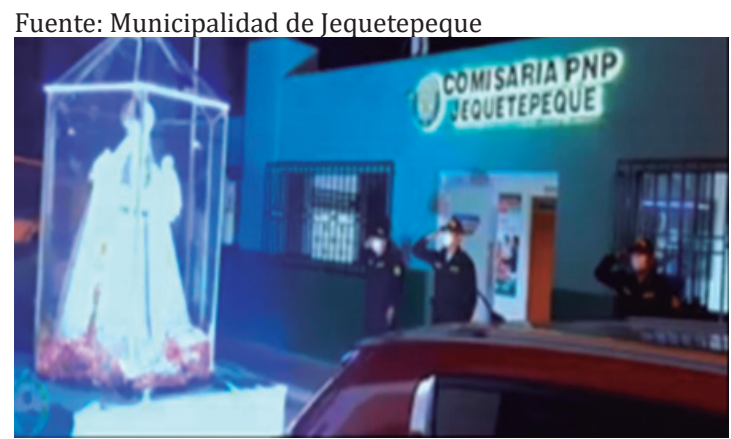

Figura 9. La religiosidad cumpliendo el rol protector hacia la policía durante la pandemia

Fuente: Municipalidad de Jequetepeque

\section{Agradecimiento}

Alex M. Carrillo "diseñador del logo de Geovisor"

\section{Referencias Bibliográficas}

Buzai, Gustavo. (2011). La Geotecnología: ¿Nuevo paradigma de la Geografía o paradigma geográfico de la ciencia?. Revista Catalana de Geografía. 16.

Chenghu Zhou, Fenzhen Su, Tao Pei, An Zhang, Yunyan Du, Bin Luo, Zhidong Cao, Juanle Wang, Wen Yuan, Yunqiang Zhu, Ci Song, Jie Chen, Jun Xu, Fujia Li, Ting Ma, Lili Jiang, Fengqin Yan, Jiawei Yi, Yunfeng Hu, Yilan Liao, Han Xiao. (2020). COVID-19: Challenges to GIS with Big Data, Geography and Sustainability. Recuperado el 16 de marzo del 2020. <http://www.sciencedirect.com/science/article/pii/S2666683920300092>.

Delgado Estrada, J. (2020) En Jequetepeque se baila marinera al son de las Neogeo - grafías del común. DESCO. https://www.desco.org.pe/en-jequetepeque-se-baila-marinera-alson-de-las-neogeo-grafias-del-comun

Delgado Estrada, J. (2019). De la geopolítica de la dominación a las geografías políticas de la des/colonialidad del poder. Espiral, Revista De Geografías Y Ciencias Sociales, 1(1), 059074. https://doi.org/10.15381/espiral.v1i1.15846

Delgado Estrada, J. (2014). Geotecnologías de la información en el Perú: historia,usos y aplicación en la educación peruana. Ar@cne. Revista electrónica de recursos en Internet sobre Geografía y Ciencias Sociales. Barcelona: Universidad de Barcelona, no 189. Recuperado el 15 de abril del 2018. <http://www.ub.es/geocrit/aracne/aracne-189.htm>.

Hine, C., Hormazábal, C., \& Hine, C. (2004). Etnografía virtual (2nd ed., pp. 9-67). Barcelona.

Restrepo,E. (2018). Etnografía, Alcances, Técnicas y Éticas (1st ed., pp. 27-45). Lima: Universidad Nacional Mayor de San Marcos, Fondo Editorial, Facultad de Ciencias Sociales.

Rockwell, E. (2015). La Experiencia etnográfica (1st ed., pp. 17-38). Buenos Aires: Paidós. 
